\title{
4E-BP1 Protects Neurons from Misfolded Protein Stress and Parkinson's Disease Toxicity by Inducing the Mitochondrial Unfolded Protein Response
}

\author{
Somasish Ghosh Dastidar, ${ }^{1,2,3}$ Michael T. Pham, ${ }^{1,2}$ Matthew B. Mitchell, ${ }^{2}$ Steven G. Yeom, ${ }^{2}$ Sarah Jordan, ${ }^{2}$ \\ Angela Chang, ${ }^{2}$ Bryce L. Sopher, ${ }^{4}$ and Albert R. La Spada ${ }^{1,2,5}$ \\ ${ }^{1}$ Departments of Neurology, Neurobiology, and Cell Biology, Duke University School of Medicine, Durham, North Carolina 27710, ${ }^{2}$ Department of \\ Pediatrics, and the Institute for Genomic Medicine, University of California, San Diego, California 92093, ${ }^{3}$ Center for Molecular Neurosciences, \\ Kasturba Medical College, Manipal, 576104, India, ${ }^{4}$ Department of Neurology, University of Washington Medical Center, Seattle, Washington \\ 98195, and ${ }^{5}$ Department of Pathology \& Laboratory Medicine and Department of Neurology, University of California, Irvine, California 92697
}

Decline of protein quality control in neurons contributes to age-related neurodegenerative disorders caused by misfolded proteins. 4EBP1 is a key node in the regulation of protein synthesis, as activated 4E-BP1 represses global protein translation. Overexpression of 4E-BP1 mediates the benefits of dietary restriction and can counter metabolic stress, and 4E-BP1 disinhibition on mTORC1 repression may be neuroprotective; however, whether 4E-BP1 overexpression is neuroprotective in mammalian neurons is yet to be fully explored. To address this question, we generated 4E-BP1-overexpressing transgenic mice and confirmed marked reductions in protein translation in 4E-BP1-overexpressing primary neurons. After documenting that 4E-BP1-overexpressing neurons are resistant to proteotoxic stress elicited by brefeldin A treatment, we exposed primary neurons to three different Parkinson's disease (PD)-linked toxins (rotenone, maneb, or paraquat) and documented significant protection in neurons from newborn male and female 4E-BP1-OE transgenic mice. We observed 4E-BP1-dependent upregulation of genes encoding proteins that comprise the mitochondrial unfolded protein response, and noted 4E-BP1 overexpression required activation of the mitochondrial unfolded protein response for neuroprotection against rotenone toxicity. We also tested whether 4E-BP1 could prevent $\alpha$-synuclein neurotoxicity by treating $4 \mathrm{E}-\mathrm{BP} 1-$ overexpressing primary neurons with $\alpha$-synuclein preformed fibrils, and we observed marked reductions in $\alpha$-synuclein aggregation and neurotoxicity, thus validating that $4 \mathrm{E}-\mathrm{BP} 1$ is a powerful suppressor of PD-linked pathogenic insults. Our results indicate that increasing 4E-BP1 expression or enhancing 4E-BP1 activation can robustly induce the mitochondrial unfolded protein response and thus could be an appealing strategy for treating a variety of neurodegenerative diseases, including especially PD.

Key words: 4E-BP1; alpha-synuclein; mitochondrial unfolded protein response; neuroprotection; Parkinson's disease; protein translation

Significance Statement

In neurodegenerative disease, misfolded proteins accumulate and overwhelm normal systems of homeostasis and quality control. One mechanism for improving protein quality control is to reduce protein translation. Here we investigated whether neuronal overexpression of 4E-BP1, a key repressor of protein translation, can protect against misfolded protein stress and toxicities linked to Parkinson's disease, and found that 4E-BP1 overexpression prevented cell death in neurons treated with brefeldin A, rotenone, maneb, paraquat, or preformed fibrils of $\alpha$-synuclein. When we sought the basis for 4E-BP1 neuroprotection, we discovered that 4E-BP1 activation promoted the mitochondrial unfolded protein response. Our findings highlight 4E-BP1 as a therapeutic target in neurodegenerative disease and underscore the importance of the mitochondrial unfolded protein response in neuroprotection against various insults.

Received Apr. 21, 2020; revised Sep. 6, 2020; accepted Sep. 10, 2020.

Author contributions: A.R.L.S. and S.G.D. designed research; A.R.L.S., M.T.P., M.B.M., S.G.Y., S.J., A.C., B.L.S., and S.G.D. analyzed data; A.R.L.S. and S.G.D. edited the paper; A.R.L.S. wrote the paper; M.T.P., M.B.M., S.G.Y., S.J., A.C., B.L.S., and S.G.D. performed research; S.G.D. wrote the first draft of the paper.

The authors declare no competing financial interests.

This work was supported by National Institutes of Health Grants R01 AG033082 and R01 NS065874 to A.R. L.S.; and Department of Biotechnology, India RLS fellowship to S.G.D. We thank K. Luk and V. Lee for providing $\alpha$-synuclein preformed fibrils; E. Lopez and A. Foley for mouse colony management assistance; and N.J. Arboleda, M.S. Shrilaxmi, J. Oh, 0. Puckett, D. Sanders, J. Hsu, A. Risbud, M. Gue, and M. Wadhwa for technical and statistical assistance.

Correspondence should be addressed to Albert R. La Spada at alaspada@uci.edu or Somasish Ghosh Dastidar at somasish.gd@manipal.edu.

https://doi.org/10.1523/NNEUROSC1.0940-20.2020

Copyright $\odot 2020$ the authors 


\section{Introduction}

More than two decades ago, research into the pathogenesis of inherited neurodegenerative disorders and sporadic neurodegenerative diseases revealed a common theme of protein misfolding as the mechanistic basis of almost all such disorders (Taylor et al., 2002). The importance of protein quality control in maintaining homeostasis in neurons and other CNS cells was further reinforced by the realization that autophagy is critically important for normal CNS function, as conditional deletion of an essential autophagy pathway gene from neurons is sufficient to produce rapidly progressive neurodegeneration in mice, accompanied by accumulation of ubiquitinated protein aggregates (Hara et al., 2006; Komatsu et al., 2006). In CNS cells subjected to the accumulation of a toxic disease-causing misfolded protein, as occurs in neurodegenerative disorders, such as Alzheimer's disease, Parkinson's disease (PD), or amyotrophic lateral sclerosis, the proteotoxic stress causes a disruption of proteostasis, resulting in altered solubility of the proteome in neurons and glia (Pace et al., 2018). While numerous studies have shown that boosting proteostasis can effectively counter such CNS dyshomeostasis, another approach would be to reduce protein translation.

The mechanistic target of rapamycin (mTOR) is a serine/ threonine protein kinase that regulates cellular growth, cytoskeletal organization, differentiation, development, survival, and aging (Maiese et al., 2013). mTOR is ubiquitously expressed (including in the CNS) and serves as the central component of two major complexes in multicellular organisms, mTORC1 and mTORC2. While mTORC2 regulates the organization of the actin cytoskeleton, activation of mTORC1 increases protein translation through activation of S6 kinase 1 and inhibition of $4 \mathrm{E}$ binding protein 1 (4E-BP1) (Lipton and Sahin, 2014). As 4E-BP1 represses the activity of eukaryotic initiation factor $4 \mathrm{E}$ (eIF4E), increased 4E-BP1 function results in reduced protein translation. Numerous studies have documented that rapamycin inhibition of mTORC1 is neuroprotective; but although this effect has often been attributed to autophagy activation, rapamycin can inhibit protein aggregation in Huntington's disease cellular models independently of autophagy by reducing protein synthesis (King et al., 2008). Furthermore, activation of 4E-BP1 alone has been shown to prevent dopaminergic neurodegeneration in a Drosophila model of PD (Tain et al., 2009). Whether $4 \mathrm{E}-\mathrm{BP} 1$ overexpression is neuroprotective in mammalian neurons is yet to be fully explored.

Here we studied a line of transgenic mice that overexpress WT 4E-BP1, and observed marked neuroprotection against protein misfolding stress, PD-linked toxin insult, and preformed fibrils (PFFs) of $\alpha$-synuclein ( $\alpha$-syn) in primary neurons overexpressing $4 \mathrm{E}-\mathrm{BP} 1$. When we examined the expression of metabolic regulators and mitochondrial stress response genes, we noted that $4 \mathrm{E}-\mathrm{BP} 1$ overexpression activated the mitochondrial unfolded protein response $\left(\mathrm{UPR}^{\mathrm{mt}}\right)$, which is a mitochondrial stress response documented to be neuroprotective in cell culture, worm, and mouse models of Alzheimer's disease (Jovaisaite et al., 2014). We confirmed that neuroprotection in neurons overexpressing 4E-BP1 depends on activation of the $\mathrm{UPR}^{\mathrm{mt}}$. These findings underscore the importance of $4 \mathrm{E}-\mathrm{BP} 1$ as a therapeutic target in neurodegenerative proteinopathies.

\section{Materials and Methods}

$4 E-B P 1$ transgenic mice. All animal experimentation adhered to National Institutes of Health guidelines and was approved by, and performed in accordance with, the University of California, San Diego and
Table 1. Primers for PCR Analysis

\begin{tabular}{|c|c|c|}
\hline Gene & Primer & Sequence \\
\hline \multirow[t]{2}{*}{ Citrate synthase } & Cs forward & 5' -CAAATCAGGAGGTGCTTGTCTGG-3' \\
\hline & Cs reverse & 5'-AGTCTCGTAACTTCTCATCTGACAC-3' \\
\hline \multirow[t]{2}{*}{ Hexokinase 1} & Hk1 forward & 5'-TCCGAGTCCTACTGGTAAAG-3' \\
\hline & Hk1 reverse & 5'-CAATGTGATCAAACAGCTCATC-3' \\
\hline \multirow[t]{2}{*}{ Pyruvate carboxylase } & Pcx forward & 5'-AAGACTTCACGGCTACCT-3' \\
\hline & Pcx reverse & $5^{\prime}$-TTCCAGCTCAACCTCAAAC-3' \\
\hline \multirow[t]{2}{*}{ Superoxide dismutase 2} & Sod2 forward & 5'-AAGGAGCAAGGTCGCTTACA-3' \\
\hline & Sod2 reverse & 5'-CAGCGGAATAAGGCCTGTTGT-3' \\
\hline \multirow[t]{2}{*}{ Superoxide dismutase 1} & Sod1 forward & 5'-TGTGACTGCTGGAAAGGACG-3' \\
\hline & Sod1 reverse & 5' -TCATGGACCACCATTGTACGG-3' \\
\hline \multirow[t]{2}{*}{ Glutathione S-transferase, mu 5} & Gstm5 forward & 5'-CCGTTTTGAGGCTTTGGAGAA-3' \\
\hline & Gstm5 reverse & $5^{\prime}$-CGAGCTCTGGCTCAGCATAA-3' \\
\hline \multirow{2}{*}{$\begin{array}{l}\text { Heat shock protein d1 (also } \\
\text { known as chaperonin aka } \\
\text { Hsp60) }\end{array}$} & Hspd1 forward & $5^{\prime}-\mathrm{GAGCAGCTAGACATCACAAC-3^{ \prime }}$ \\
\hline & Hspd1 reverse & 5' -CAGTTGTTCCTCCAACCTTC-3' \\
\hline \multirow{2}{*}{$\begin{array}{l}\text { Caseinolytic mitochondrial matrix } \\
\text { peptidase proteolytic subunit }\end{array}$} & ClpP forward & $5^{\prime}$-AGCCACAGACATCGCCATC-3' \\
\hline & ClpP reverse & 5' -CCATTGCTGACTCGATCACCTG-3' \\
\hline \multirow{2}{*}{$\begin{array}{l}\text { Caseinolytic mitochondrial matrix } \\
\text { peptidase chaperone subunit }\end{array}$} & ClpX forward & $5^{\prime}$-GGATACATTCGGGCACCCTC-3' \\
\hline & ClpX reverse & 5' -CTGTTTGCAGCATCCGCTTG-3' \\
\hline \multirow[t]{2}{*}{ 4EBP1 } & 4EBP1 forward & 5'-CAGGCGGTGAAGAGTCA-3' \\
\hline & 4EBP1 reverse & 5'-AGTGTCTGCCTGGTATGAG-3' \\
\hline \multirow[t]{2}{*}{ C/EBP homologous protein } & CHOP forward & $5^{\prime}$-AGCCAGAATAACAGCCGGAAC-3' \\
\hline & CHOP reverse & 5'-GACCAGGTTCTGCTTTCAGG-3' \\
\hline \multirow{2}{*}{$\begin{array}{l}\text { CCAAAT/enhancer binding protein } \\
\text { beta }\end{array}$} & Cebpb forward & 5' -ACTTGATGCAATCCGGATCAAAC-3' \\
\hline & Cebpb reverse & 5'-CAGTTACACGTGTGTTGCGT-3' \\
\hline \multirow[t]{2}{*}{ PPAR $\gamma$ coactivator 1-alpha } & Ppara forward & 5' -TGCATTTGGGCGTATCTCAC-3' \\
\hline & Ppara reverse & 5' -AACTTCAACTTGGCTCTCCTC-3' \\
\hline \multirow[t]{2}{*}{ Active transcription factor 4} & Atf4 forward & 5'-CGGCAAGGAGGATGCCTTTT-3' \\
\hline & Atf4 reverse & 5'-TGGCATGGTTTCCAGGTCAT-3' \\
\hline
\end{tabular}

University of California, Irvine Institutional Animal Care and Use Committees and the Duke University Committee on the Use and Care of Animals. 4E-BP1-OE transgenic lines were maintained on the C57BL/ 6J strain background.

Primary cortical neuron culture experiments. Primary cortical neurons were cultured from dissociated cortex of postnatal day 0 (P0) to day 1 (P1) mice, as described previously (Dubinsky et al., 2014). The dissociation was done using trypsin (T9935), trypsin inhibitor (T6522), and DNase I (10104159001, Roche Diagnostics). Primary neurons were seeded onto plates coated with $0.1 \mathrm{mg} / \mathrm{ml}$ poly-D-lysine hydrobromide (P1024-50MG) and grown in complete media (CM) consisting of Neurobasal-A medium (Thermo Fisher Scientific, 10888022) supplemented with $0.5 \mathrm{~mm} \mathrm{L-}$ glutamine (Thermo Fisher Scientific, 25030149), 0.25\% penicillinstreptomycin (Thermo Fisher Scientific, 15140148), and 0.25\% B-27 supplement (Thermo Fisher Scientific, 17504001). Primary neurons were maintained until treatment by removing half of the CM and replacing it with fresh $\mathrm{CM}$ on day 3 (where day 0 is the day of cell seeding), day 5 , and every second day after day 5 . For SUnSET assay, neurons were treated with puromycin for $10 \mathrm{~min}(10 \mu \mathrm{g} / \mathrm{ml})$, followed by incubation in puromycin-free media for $20 \mathrm{~min}$. On day 14 , primary neurons were treated for $5 \mathrm{~h}$ with $50 \mu \mathrm{g} / \mathrm{ml}$ brefeldin A (B5936). Treatment with $10 \mu \mathrm{M}$ paraquat, $1 \mu \mathrm{M}$ maneb, or $0.1 \mu \mathrm{M}$ rotenone was done on day 14 (DIV 14) followed by immunoblot, propidium iodide staining, or $\mathrm{LDH}$ assay. Primary hippocampal neurons were prepared in a similar manner as the cortical neurons; and in both cases, we used comparable numbers of males and females between 4E-BP1 transgenic and WT littermate control mice. Briefly, the hippocampus from P0 mice was dissected, meninges removed, dissociated into single cells, and maintained in the same manner as primary cortical neurons. The primary hippocampal neurons were seeded with preformed $\alpha$-syn fibrils at a 
A



C

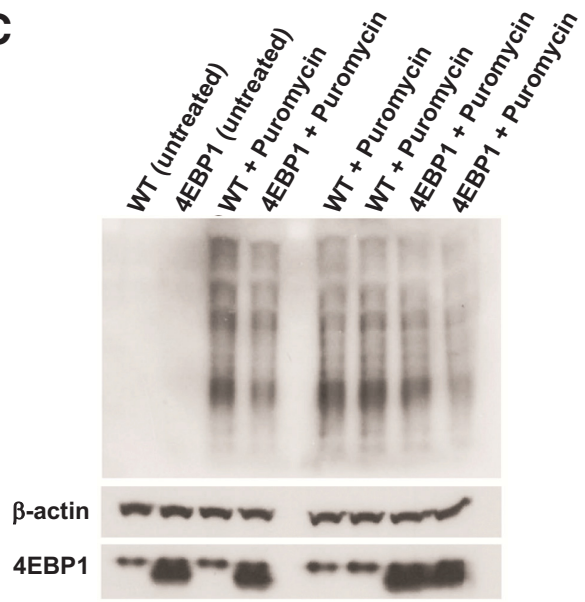

D

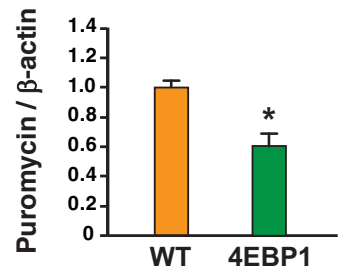

Figure 1. Protein translation is markedly reduced in 4E-BP1-overexpressing neurons. $A$, DIV14 primary cortical neurons from control and 4E-BP1 transgenic mice were treated with puromycin $(10 \mu \mathrm{g} / \mathrm{ml}$ for $10 \mathrm{~min})$, immunostained with antipuromycin antibody, and counterstained with DAPI. Puromycin immunoreactivity is visibly decreased in primary neurons from 4E-BP1 transgenic mice. Scale bar, $10 \mu \mathrm{m}$. B, Densitometry analysis of puromycin immunostaining analysis shown in $\boldsymbol{A} . n=3$ biological replicates; $n=4$ technical replicates/culture. ${ }^{*} p=0.020$ (two-tailed $t$ test; $\mathrm{df}=21$; EF = 1.1). C, DIV14 primary cortical neurons were treated with puromycin (10 $\mu \mathrm{g} / \mathrm{ml}$ for $10 \mathrm{~min})$ and then harvested for protein isolation followed by SDS-PAGE and immunoblotting with antipuromycin antibody. Puromycin immunoreactivity is visibly decreased in primary neurons from 4E-BP1 transgenic mice. $\beta$-actin served as a loading control, and transgene status was confirmed by immunoblotting for 4E-BP1. D, Densitometry analysis of puromycin immunoblotting analysis shown in $\boldsymbol{C}$. $n=3$ biological replicates. ${ }^{*} p=0.014$ (two-tailed $t$ test; df $=4$; $\mathrm{EF}=5.7)$. Error bars indicate SEM.

concentration of $100 \mathrm{ng} / \mathrm{ml}$ on day 10 and maintained for an additional $7 \mathrm{~d}$, before immunocytochemistry was conducted with purified anti- $\alpha$-syn phospho (Ser129) antibody 81A (825701, BioLegend; previously Covance catalog \#MMS-5091) as described previously (Luk et al., 2009, 2012).

LDH and propidium iodide assays. The LDH assay was conducted using LDH-Cytotoxicity Assay Kit II (BioVision, K313-500-2) according to the manufacturer's instructions. Briefly, LDH Assay Buffer and WST Substrate Mix were added to media harvested from primary neurons. Plate readings were taken at four time points: 30,60 , 90, and $120 \mathrm{~min}$. The percent of LDH released was calculated as the percent cytotoxicity over the amount of protein $(\mu \mathrm{g} / \mu \mathrm{l})$. Amount of protein was separately determined using BCA assay using the Pierce BCA Protein Assay Kit (catalog \#23225). For the High Control, cells were treated with $10 \mu \mathrm{l}$ of the cell lysis buffer provided with the LDH assay kit and kept in the incubator for $20 \mathrm{~min}$ before the media was harvested for LHD assay. For the Low Control, the cells/neurons were treated with complete media for neuronal growth. After harvesting media, cells were treated with propidium iodide (P4864, 1:3000) and Hoechst $(33342,1: 10,000)$ and kept in the incubator for $15 \mathrm{~min}$ before imaging each well under a 780 LSM confocal microscope (Carl Zeiss) at $10 \times$ or Keyence BZ-X710. Briefly, three images were taken per well, and each experiment was done in triplicate and repeated 3 times independently, unless otherwise mentioned.

$J C-1$ assay. Primary neurons were treated with $50 \mu \mathrm{g} / \mu \mathrm{l}$ brefeldin A (B5936) in CM, or CM alone for $5 \mathrm{~h}$. Primary neurons were also incubated with $30 \mu \mathrm{M}$ carbonyl cyanide 3-chlorophenylhydrazone (C2759, Sigma Millipore) for $20-30 \mathrm{~min}$ at $37^{\circ} \mathrm{C}$. This was followed by incubation with $100 \mu \mathrm{M}$ JC-1 dye (Calbiochem, catalog \#420200) at $37^{\circ} \mathrm{C}$ for $20-$ $30 \mathrm{~min}$. Following this, the cells were washed carefully 3 times with warm PBS buffer before the fluorimetric reading was taken. Red to green ratio was measured using Tecan infinite M200 pro. JC-1 dye exhibits potential-dependent accumulation in mitochondria, indicated by a fluorescence emission shift from green $(\sim 529 \mathrm{~nm})$ to red $(\sim 590 \mathrm{~nm})$. A decrease in the red/green ratio indicates mitochondrial depolarization.

Lentivirus preparation and transduction. Validated lentiviral pLKO.1 vectors harboring shRNA against Chop (SHCLNG NM_007837), Cebp $\beta$ (SHCLNG NM_009883), and Hspd1 (SHCLNG NM_010477) specific against mouse gene targets were ordered from Sigma Millipore; $7.5 \mu \mathrm{g}$ of shRNA plasmids was purified and cotransfected with $7.5 \mu \mathrm{g}$ LP1, LP2, and VSVG plasmids in a $15 \mathrm{~cm}$ dish with $70 \%$ confluent HEK293FT using Lipofectamine 2000 according to the manufacturer's protocol. Six hours later, the media was changed to media without antibiotics and the virus was harvested $48 \mathrm{~h}$ after transfection from the media. Briefly, the media was filter sterilized $(0.45 \mu \mathrm{m}$ filter $)$ and subjected to $20 \%$ sucrose gradient centrifugation (the media was put in the ultracentrifuge tube, followed by addition of $2 \mathrm{ml}$ of sucrose at the bottom of the well) at 20,000 rpm at $4^{\circ} \mathrm{C}$ for $2 \mathrm{~h}$. The media was removed along with the sucrose solution and a light pellet was observed which was solubilized in ice-cold PBS. Lentivirus was used at 30-50 multiplicity of infection. Prepared lentivirus was infected in primary cortical neurons $7 \mathrm{~d}$ after plating. On day 14 , the neurons were treated with rotenone before subjecting them to propidium iodide staining or LDH assay. For knockdown efficiency testing, the infected neurons were harvested on day 14 by Trizol and subjected to RTPCR analysis.

$R T-P C R$. RNA was harvested from cultured primary neurons using TRIzol Reagent (Thermo Fisher Scientific, 15596018) according to the manufacturer's instructions; $1 \mu \mathrm{g}$ of RNA was used to prepare cDNA using USB First-Strand cDNA Synthesis Kit (USB products, catalog \#75780) or Superscript II First strand (Invitrogen, catalog \#1701598) for Real-Time PCR according to the manufacturer's instructions. PCR was performed using SYBR Green (Thermo Fisher Scientific, 4367659). A complete list of primers follows is given in Table 1.

Immunoblot analysis and immunohistochemistry. Western blotting was done as previously described (Dubinsky et al., 2014). Briefly, cell 
A


B

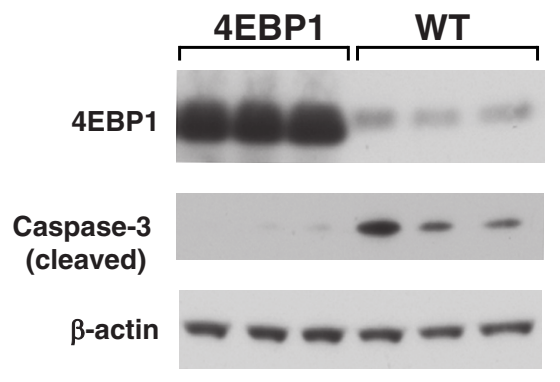

C

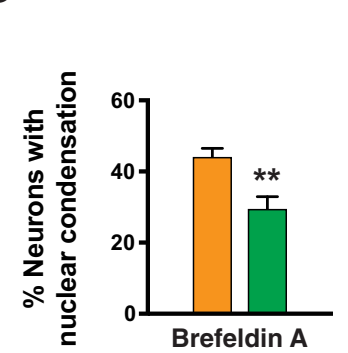

WT

4EBP1

Figure 2. 4E-BP1-overexpressing neurons are protected against brefeldin A proteotoxicity. A, DIV14 primary cortical neurons from control and 4E-BP1 transgenic mice were treated with brefeldin $A(50 \mu \mathrm{g} / \mathrm{ml})$, immunostained with antibodies against activated caspase-3 and MAP2, and counterstained with DAPI (4',6-diamidino-2-phenylindole). Cell death is visibly decreased in primary neurons from 4E-BP1 transgenic mice, based on decreased activated caspase-3 nuclear staining and increased MAP2 neurite staining. Scale bar, $10 \mu \mathrm{m}$. B, DIV14 primary cortical neurons from control and 4E-BP1 transgenic mice were treated with brefeldin $A(50 \mu \mathrm{g} / \mathrm{ml})$, and then harvested for protein isolation followed by SDS-PAGE and immunoblotting with anti-activated caspase-3 antibody. Caspase-3 activation is visibly decreased in primary neurons from 4E-BP1 transgenic mice. $\beta$-Actin served as a loading control, and transgene status was confirmed by immunoblotting for 4E-BP1. Right, Densitometry analysis of activated caspase-3 immunoblotting. $n=3$ biological replicates; $n=2$ technical replicates. ${ }^{* *} p=0.007$ (two-tailed $t$ test; $\mathrm{df}=12 ; \mathrm{EF}=1.9$ ). C, DIV14 primary cortical neurons from control and 4E-BP1 transgenic mice were treated with brefeldin $A(50 \mu \mathrm{g} / \mathrm{ml})$, and counterstained with DAPI as in $A$. We then counted the number of neurons showing nuclear condensation. $n=4$ biological replicates; $n \geq 50$ neurons. ${ }^{* *} p=0.008$ (two-tailed $t$ test; $\mathrm{df}=8 ; \mathrm{EF}=2.6$ ). D, DIV14 primary cortical neurons from control and 4E-BP1 transgenic mice were treated with brefeldin A ( $50 \mu \mathrm{g} / \mathrm{ml}$ ), immunostained with antibodies against activated caspase-3 and MAP2, and counterstained with DAPI as in $\boldsymbol{A}$. We then counted the number of neurons showing activated caspase-3 nuclear staining. $n=4$ biological replicates; $n \geq 50$ neurons. ${ }^{* *} p=0.001$ (two-tailed $t$ test; $\mathrm{df}=8 ; \mathrm{EF}=3.7$ ). Error bars indicate SEM.

lysates were prepared using $1 \times$ RIPA buffer (Thermo Scientific Pierce, PI89901) plus protease inhibitor tablets (4693124001) and phosphatase inhibitor tablets (4906837001). Equivalent amounts of protein (10-25 $\mathrm{gg}$ ) from each sample were mixed with $4 \times$ LDS sample buffer (Thermo Fisher Scientific, NP0007), 10× Reducing agent (Thermo Fisher Scientific, NP0009), and $1 \times$ RIPA buffer. The sample mixtures were heated for $10 \mathrm{~min}$ at $70^{\circ} \mathrm{C}$, subjected to SDS-PAGE (sodium dodecyl sulphate-polyacrylamide gel electrophoresis), and transferred onto a PVDF membrane. The membranes were blocked for $1 \mathrm{~h}$ with $5 \%$ nonfat dry milk in PBS plus
$0.1 \%$ Tween 20 (Thermo Fisher Scientific, BP337500) and then incubated with primary antibodies overnight at $4^{\circ} \mathrm{C}$. This was followed by incubation with secondary antibodies for $1 \mathrm{~h}$ at room temperature. Chemiluminescent substrate was added to the blot, and chemiluminescence was detected using autoradiography.

For immunohistochemistry, all reagents were prepared in PBS. Coverslips with primary neurons were fixed with 4\% PFA (Electron Microscopy Sciences, 15714) for $20 \mathrm{~min}$, followed by addition of $0.2 \%$ Triton (T8787) for $5 \mathrm{~min}$. Blocking was done in a solution of $5 \%$ BSA (A7906) plus 5\% goat serum (Jackson ImmunoResearch Laboratories, 005-000-121) for $1 \mathrm{~h}$ at room temperature. Primary antibodies were diluted with $5 \%$ BSA plus $5 \%$ goat serum. Incubation with primary antibodies was done overnight at $4^{\circ} \mathrm{C}$. Secondary antibodies were prepared in 5\% BSA plus $5 \%$ goat serum. Incubation with secondary antibodies was for $1 \mathrm{~h}$ at room temperature. Coverslips with primary neurons were incubated in Hoechst 33342 (Thermo Fisher Scientific, H3570) at a $1: 10,000$ dilution for $10 \mathrm{~min}$ at room temperature before mounting them on Fluoromount $G$ (Electron Microscopy Sciences, catalog \#17984-25). The fixed cells were imaged using a $63 \times$ objective in an LSM 780 confocal microscope (Carl Zeiss). For immunocytochemistry of hippocampal neurons treated with $100 \mathrm{ng} / \mathrm{ml}$ of $\alpha$-syn PFFs, neurons were fixed with $4 \% \mathrm{PFA}, 4 \%$ sucrose, and $1 \%$ Triton X-100. Following fixation, neurons were blocked with 5\% BSA in PBS, and incubated in primary antibody followed by AlexaFluor-488-conjugated secondary antibodies.

Unless indicated otherwise, all antibodies were purchased from Sigma Millipore. Primary antibodies used in this study were as follows: $\beta$-actin (Abcam, ab8226, 1:5000), 4E-BP1 (Cell Signaling Technology, 9644S, 1:1000), Hsp60 (Cell Signaling Technology, 12165S, 1:7500), cleaved caspase-3 (Cell Signaling Technology, 9664S, 1:1000), $\alpha$-syn (BioLegend, previously Covance catalog \#MMS-5091, 1:400 for IC), cleaved caspase-3 (Cell Signaling Technology, 9664S, 1:400 for IC), microtubule-associated protein 2 (MAP2 [microtubule-associated protein 2], Millipore, MAB3418, 1:400 for IC), puromycin (Millipore, MABE343, 1:1000), and 4EBP1 (Cell Signaling Technology, 9644S,1:400). For Western blot analysis, primary antibodies were used at a dilution of 1:1000 and secondary antibodies (from Santa Cruz Biotechnology) were used at concentrations ranging from 1:5000 to $1: 10,000$. For immunocytochemistry, primary antibodies were used at a concentration of 1:400 and secondary antibodies (from Thermo Fisher Scientific) were used at a 1:100 dilution.

Experimental design and statistical analysis. All the graphs in this study were generated using GraphPad Prism 6 software. Statistical analysis was done using Microsoft Excel, Prism 6.0 (GraphPad), and SigmaPlot (Systat Software). Statistical significance was defined at $p<0.05$. All $t$ tests were two-tailed Student's $t$ tests, and level of significance $(\alpha)$ was always set to 0.05 . For one-way and two-way ANOVA, if statistical significance $(p<0.05)$ was achieved, then we performed post hoc analysis, as specified, to account for multiple comparisons. Details of each experiment, including the number of 
biological replicates and technical replicates, as well as the number of neurons analyzed, are provided in each figure legend. In addition to exact $p$ values, figure legends include the degrees of freedom and effect size (EF) for each statistical comparison.

\section{Results}

4E-BP1 overexpression in neurons yields a marked reduction in protein translation

To examine the role of protein translation status as a modifier of disease, we generated $4 \mathrm{E}-\mathrm{BP} 1$ transgenic mice in which a loxPflanked STOP codon cassette is placed $5^{\prime}$ to the $4 E-B P 1$ transgene and 3' to the CAGGS promoter-enhancer (Tsai et al., 2015). These $4 E-B P 1$ conditional transgenic mice were bred to CMVCre transgenic mice to yield a line of $4 E-B P 1-O E$ mice that display whole-body fourfold to fivefold overexpression of 4E-BP1, which was confirmed by immunoblot analysis of various tissues (Tsai et al., 2015, 2016). To determine the effect of 4E-BP1 overexpression on protein translation in neurons of $4 E-B P 1-O E$ mice, we derived primary cortical neurons from $4 E-B P 1-O E$ mice and nontransgenic WT littermate controls, and treated the cultured cortical neurons with a brief pulse of puromycin to monitor protein translation via SUnSET assay (Schmidt et al., 2009). As puromycin is a structural analog of aminoacyl tRNAs, it gets incorporated into nascent polypeptide chains, prevents further elongation of the translating protein, and can be detected by antibody staining. Immunohistochemistry analysis of puromycin-treated primary cortical neurons revealed visibly decreased puromycin immunostaining in primary cortical neurons from $4 E-B P 1-O E$ mice (Fig. $1 A$ ), and quantification of puromycin immunoreactivity confirmed a marked reduction in cortical neurons overexpressing 4E-BP1 (Fig. 1B). To corroborate these findings, we also performed immunoblot analysis of protein lysates from puromycin-treated primary cortical neurons from $4 E-B P 1-O E$ mice and WT littermate controls, and observed decreased puromycin-labeled protein in neurons overexpressing $4 \mathrm{E}$ BP1 (Fig. 1C). Densitometry analysis of puromycin immunoblots similarly confirmed a significant reduction in protein translation in primary cortical neurons from $4 E$ $B P 1-O E$ mice (Fig. 1D).

\section{E-BP1-overexpressing neurons are protected against brefeldin A-mediated proteotoxicity and are resistant to treatment with PD-linked environmental toxins}

Proteostasis is essential for optimal cell growth and survival, dysregulation of which causes protein aggregation and is associated with age-related neurodegenerative disease (Labbadia and Morimoto, 2015). One possible remedy for proteostasis decompensation in neurodegenerative proteinopathies would be to reduce protein synthesis and promote protein refolding capacity. To determine whether 4E-BP1 overexpression can counter impaired protein quality control, we treated primary cortical neurons from $4 E-B P 1-O E$ mice and WT littermate controls with brefeldin $\mathrm{A}$, a fungal metabolite known to inhibit protein secretion in eukaryotic cells by interfering with the function of the Golgi apparatus leading to proteotoxic endoplasmic reticulum stress (Fujiwara et al., 1988). Immunostaining of brefeldin A-treated cortical neurons for activated caspase-3 and MAP2 revealed obviously reduced neurotoxicity in 4E-BP1overexpressing neurons (Fig. 2A,B). Quantification of neurotoxicity by the presence of nuclear condensation and by detection of activated caspase- 3 in individual neurons confirmed that $4 \mathrm{E}-\mathrm{BP} 1$ overexpression can significantly protect

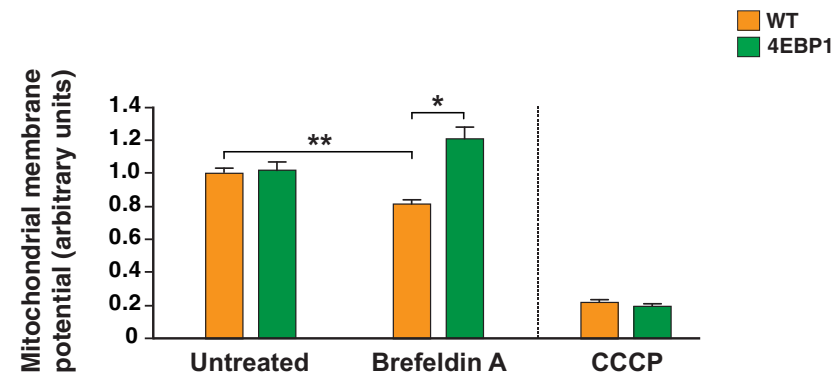

Figure 3. 4E-BP1-overexpressing neurons maintain normal mitochondrial membrane depolarization on brefeldin A-mediated proteotoxicity. DIV14 primary cortical neurons from control and 4E-BP1 transgenic mice were treated with brefeldin $A(50 \mathrm{mg} / \mathrm{ml})$, treated with $\mathrm{JC}-1$ dye, and then fluorescence emission measured to determine the extent of mitochondrial membrane depolarization. Results were normalized to nontransgenic (WT) neurons at baseline (untreated). Carbonyl cyanide m-chlorophenyl hydrazine (CCCP) treatment served as a positive control for depolarization. ANOVA with post hoc Tukey test: ${ }^{* *} p=0.001$ for WT untreated versus WT brefeldin A-treated ( $\mathrm{df}=4$, $\mathrm{EF}=0.9) .{ }^{*} p=0.012$ for WT brefeldin A treated versus $4 \mathrm{EBP} 1$ brefeldin A-treated $(\mathrm{df}=4, \mathrm{EF}=2.6)$. Error bars indicate SEM.

against general proteotoxic stress induced by brefeldin $\mathrm{A}$ treatment (Fig. 2C,D). In addition to promoting apoptotic activation, brefeldin A treatment also resulted in significant mitochondrial membrane depolarization, which was rescued in primary cortical neurons overexpressing 4E-BP1 (Fig. 3).

As proteotoxic stress in neurodegenerative proteinopathies may result in impaired general proteostasis, we reasoned that a reduced burden of newly synthesized proteins, as occurs on $4 \mathrm{E}-\mathrm{BP} 1$ overexpression, could be neuroprotective in neurodegenerative disorders involving protein misfolding. PD is a progressive neurodegenerative disorder characterized by slowness of movement, rigidity, and tremor because of the selective loss of dopaminergic neurons in the substantia nigra, and in most cases likely results from $\alpha$-syn misfolding (Dawson and Dawson, 2003). Rotenone is an insecticide and has been shown to produce parkinsonism in rodents in association with the formation of $\alpha$-syn aggregate inclusions, which may reflect rotenone's ability to alter $\alpha$-syn protein conformation (Betarbet et al., 2000; Sherer et al., 2003). In addition to rotenone, other environmental toxins prominently implicated in PD pathogenesis in rodent modeling include maneb and paraquat, which produce motor abnormalities in treated rodents, presumably because of altered dopamine metabolism, but do not elicit $\alpha$-syn inclusion formation (Roede and Jones, 2014). To determine whether 4E-BP1 overexpression can protect against these PD-linked toxins, we treated primary cortical neurons from $4 E-B P 1-O E$ mice and WT littermate controls with rotenone, maneb, or paraquat, and we observed a dramatic increase in neurotoxicity in cortical neurons treated with each of these toxins (Fig. $4 A$ ). In all 3 cases, 4E-BP1 overexpression significantly blunted the neurotoxicity based on propidium iodide exclusion and LDH release assays (Fig. $4 A, B)$. As rotenone can promote $\alpha$-syn inclusion formation, we studied rotenone treatment of primary cortical neurons further by performing immunostaining for activated caspase- 3 and MAP2, and observed visibly reduced neurotoxicity in 4E-BP1-overexpressing neurons (Fig. 4C). Quantification of neurotoxicity by the presence of nuclear condensation and detection of activated caspase- 3 in individual neurons confirmed that $4 \mathrm{E}$ BP1 overexpression can protect against rotenone toxicity (Fig. $4 D, E)$. 

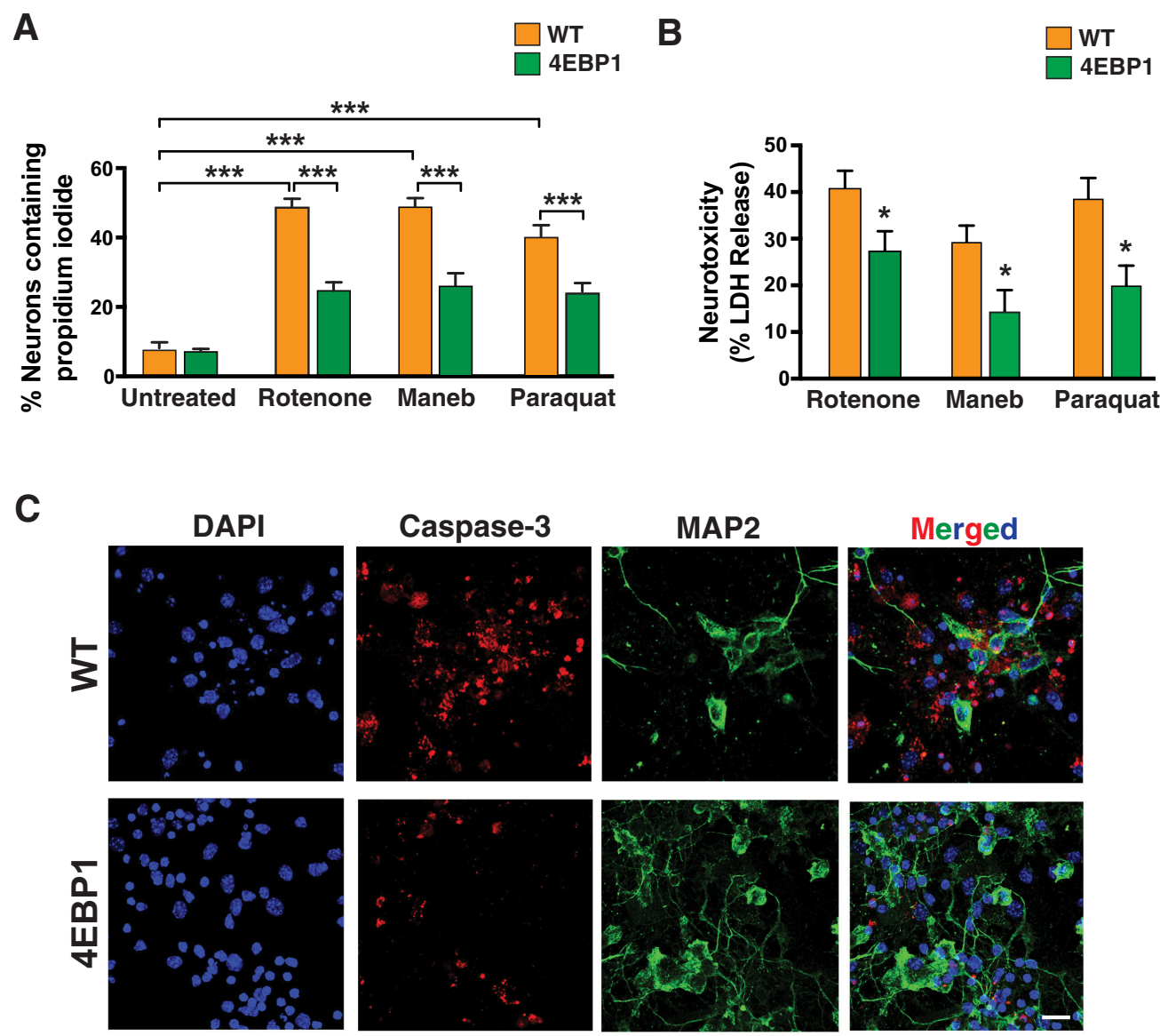

D



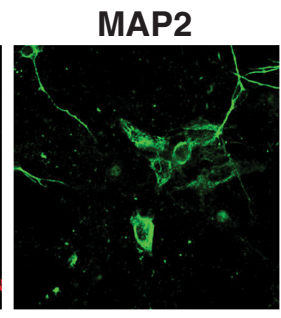
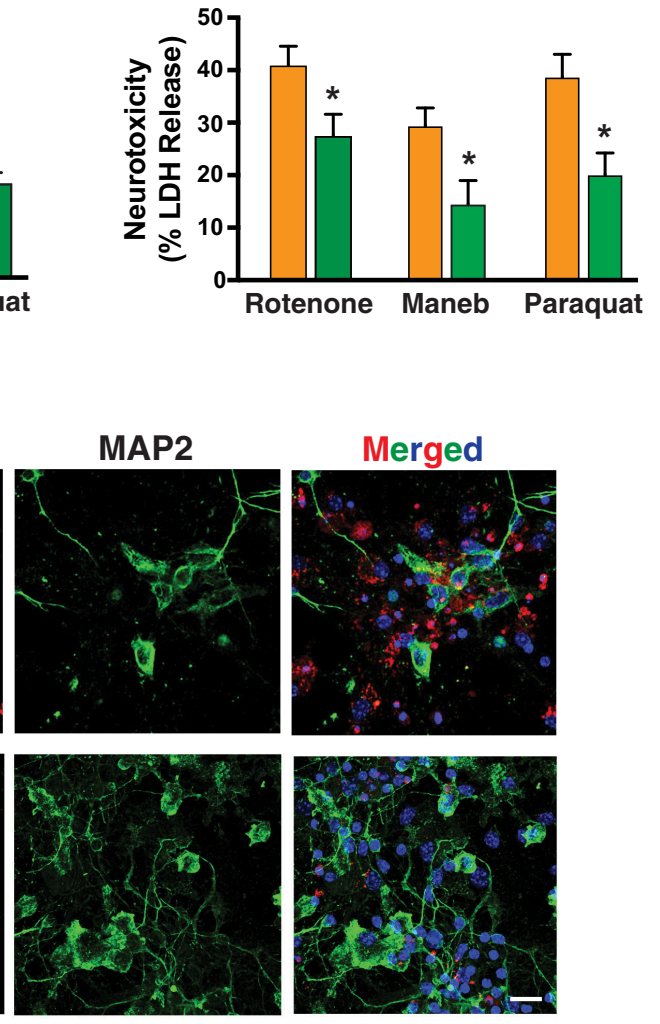

$\mathbf{E}$

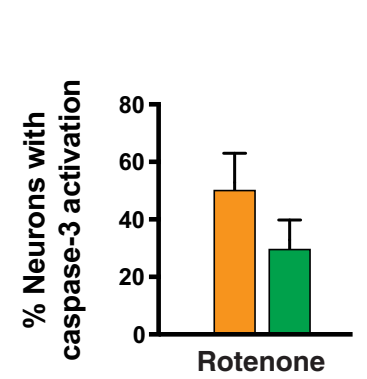

Figure 4. 4E-BP1-overexpressing neurons are protected against PD-associated environmental toxins. $A$, DIV14 primary cortical neurons from control and 4E-BP1 transgenic mice were treated with rotenone $(10 \mathrm{~nm})$, maneb $(1 \mu \mathrm{m})$, or paraquat $(10 \mu \mathrm{m})$, or left untreated. We then measured neurotoxicity by propidium iodide exclusion. $n \geq 3$ biological replicates. ANOVA with post hoc Tukey test: ${ }^{* *} p=0.0001$ for WT untreated versus WT rotenone-treated ( $\mathrm{df}=63, \mathrm{EF}=3.1$ ). ${ }^{* * *} p=0.0001$ for WT untreated versus WT maneb-treated (df $=63$, EF $=20.4$ ). ${ }^{* * *} p=0.0001$ for WT untreated versus WT paraquat-treated ( $\left.\mathrm{df}=63, \mathrm{EF}=22.1\right)$. ${ }^{* *} p=0.0001$ for WT rotenone-treated versus 4EBP1 rotenone-treated (df $\left.=69, \mathrm{EF}=1.8\right)$. ${ }^{* * *} p=0.0001$ for WT maneb-treated versus 4EBP1 maneb-treated ( $\mathrm{df}=71, \mathrm{EF}=11.6) .{ }^{* * *} p=0.0001$ for WT paraquat-treated versus 4EBP1 paraquat-treated (df $\left.=70, \mathrm{EF}=10.7\right) . \boldsymbol{B}, \mathrm{DIV} 14 \mathrm{primary}$ cortical neurons from control and 4E-BP1 transgenic mice were treated with rotenone $(10 \mathrm{nM})$, maneb $(1 \mu \mathrm{m})$, or paraquat $(10 \mu \mathrm{m})$. We then measured neurotoxicity by quantifying LDH release into the culture media. $n \geq 3$ biological replicates. Two-tailed $t$ test: ${ }^{*} p=0.041$ for WT rotenone-treated versus 4EBP1 rotenone-treated (df $\left.=7, \mathrm{EF}=1.7\right)$. ${ }^{*} p=0.027$ for WT maneb-treated versus 4EBP1 maneb-treated $(\mathrm{df}=7, \mathrm{EF}=1.0)$. ${ }^{*} p=0.018$ for WT paraquat-treated versus 4EBP1 paraquat-treated $(\mathrm{df}=7, \mathrm{EF}=0.4)$. C, DIV14 primary cortical neurons from control and 4E-BP1 transgenic mice were treated with rotenone $(10 \mathrm{nM})$, immunostained with antibodies against activated caspase-3 and MAP2, and counterstained with DAPI. Cell death is visibly decreased in primary neurons from 4E-BP1 transgenic mice, based on decreased activated caspase-3 nuclear staining and increased MAP2 neurite staining. Scale bar, $10 \mu \mathrm{m}$. D, DIV14 primary cortical neurons from control and 4E-BP1 transgenic mice were treated with rotenone $(10 \mathrm{~nm})$, and counterstained with DAPI as in C. We then counted the number of neurons showing nuclear condensation. $n=3$ biological replicates; $n \geq 50$ neurons. ${ }^{*} p=0.048$ (two-tailed $t$ test; $\mathrm{df}=4$; $\mathrm{EF}=2.8$ ). $E$, DIV14 primary cortical neurons from control and 4E-BP1 transgenic mice were treated with rotenone $(10 \mathrm{nM})$, immunostained with antibodies against activated caspase-3 and MAP2, and counterstained with DAPI as in $\boldsymbol{C}$. We then counted the number of neurons showing activated caspase-3 nuclear staining. $n=3$ biological replicates; $n \geq 50$ neurons. $p=0.083$ (two-tailed $t$ test; $\mathrm{df}=4$; $\mathrm{EF}=2.4$ ). Error bars indicate SEM.

4E-BP1 induces the expression of genes required for metabolism, antioxidant defense, and the UPR ${ }^{\mathrm{mt}}$, as well as their transcription factor regulators

While reduction of protein translation by $4 \mathrm{E}-\mathrm{BP} 1$ overexpression is a key factor in achieving neuroprotection, this mechanism alone is unlikely to account for protection against rotenone, maneb, and paraquat, where altered dopamine metabolism, increased ROS production, and impaired energy production have all been implicated (Drechsel and Patel, 2008). To assess whether $4 \mathrm{E}-\mathrm{BP} 1$ neuroprotection has a transcriptional 
A Citrate synthase
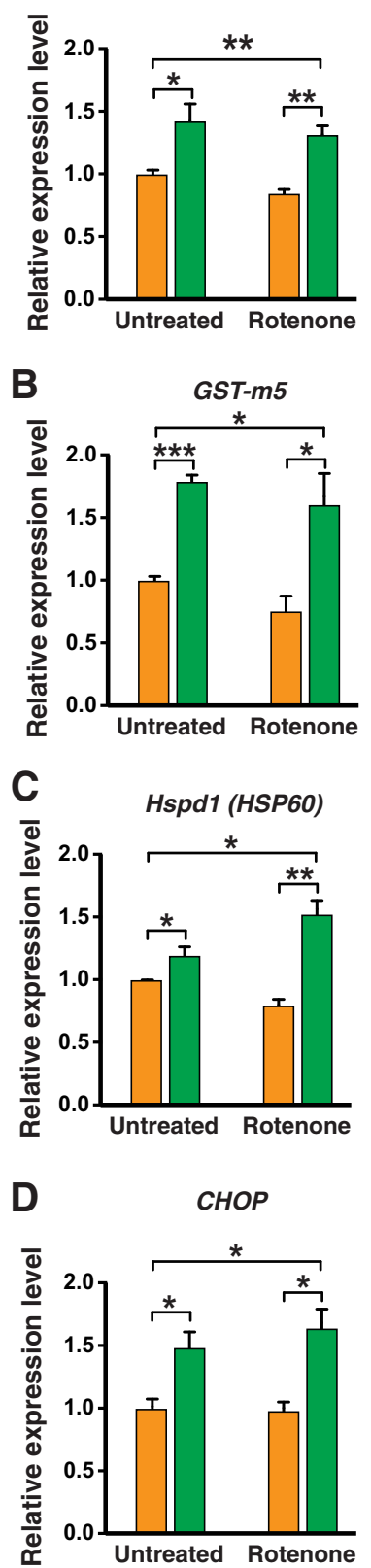

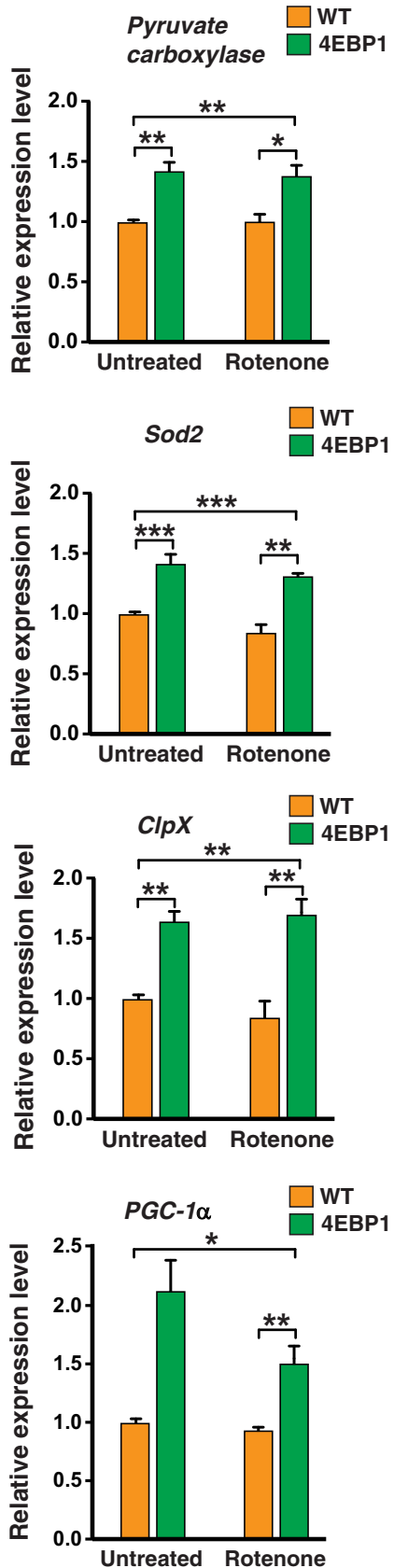

Figure 5. 4E-BP1 induces the expression of genes required for metabolism, antioxidant defense, the UPR ${ }^{m t}$, and positive transcription factor regulators of these pathways. A-D, We isolated RNA from DIV14 primary cortical neurons from control and 4E-BP1 transgenic mice that were left untreated or treated with rotenone (10 nM). We performed qRT-PCR analysis on isolated RNAs for various genes as indicated, comprising four categories: $(\boldsymbol{A})$ metabolism; $(\boldsymbol{B})$ antioxidant defense; $(\boldsymbol{C})$ UPR $^{\mathrm{mt}}$; and $(\boldsymbol{D})$ positive transcription factors regulators of the UPRmt and mitochondria biogenesis. $n=3$ biological replicates. ${ }^{*} p<0.05$; ${ }^{* *} p<0.01$; ${ }^{* *} p<0.001$; ANOVA with post hoc Tukey test. Error bars indicate SEM. For degrees of freedom, EFs, and exact $p$ values for Figure 5, see Extended Data Figure 5-1.

component affecting these pathways, we measured the expression of key regulators from these pathways, beginning with metabolic enzymes involved in glycolysis and TCA cycle function. We observed significant increases in the expression levels of citrate synthase, hexokinase 1 , and pyruvate carboxylase in 4E-BP1-overexpressing primary cortical neurons compared with WT littermate control neurons (Fig. 5A). Importantly, these 4E-BP1-dependent expression changes persisted in rotenone-treated neurons (Fig. $5 A$ ). We next considered antioxidant factors and noted significant expression increases in the glutathione-S-transferase subunit gene, superoxide dismutase 1 , and superoxide dismutase 2 in 4E-BP1overexpressing neurons, and confirmed that these expression increases were also present in 4E-BP1-overexpressing neurons exposed to rotenone (Fig. $5 B$ ). As recent work has highlighted the importance of the UPR ${ }^{\mathrm{mt}}$ in promoting proteostasis in stress situations and in neurodegenerative proteinopathies (Nargund et al., 2012; Sorrentino et al., 2017), we then analyzed the expression levels of factors involved in the UPR ${ }^{\mathrm{mt}}$, and documented marked increases in the expression of heat shock protein $\mathrm{d} 1$ (HSP60), mitochondrial ATP-dependent Clp protease proteolytic subunit $(C l p P)$, and mitochondrial ATP-dependent Clp protease ATPbinding subunit clpX-like $(C l p X)$ in primary cortical neurons from $4 E-B P 1-O E$ mice compared with WT littermate control mice, and documented increased expression of $\mathrm{UPR}^{\mathrm{mt}}$ mediators, 
which was sustained in 4E-BP1-overexpressing neurons exposed to rotenone (Fig. $5 C$ ). As the genes that encode factors comprising the $U_{P R}{ }^{\mathrm{mt}}$ contain a response element corresponding to the consensus binding site of a transcription factor known as the CCAAT/enhancer-binding protein homologous protein (CHOP), and previous studies have documented that CHOP expression itself is upregulated during the $\mathrm{UPR}^{\mathrm{mt}}$ (Zhao et al., 2002), we measured $C H O P$ expression in $4 \mathrm{E}-\mathrm{BP} 1$-overexpressing neurons, and observed significant induction compared with WT neurons (Fig. 5D). We also found that 4E-BP1-overexpressing neurons display elevated expression of ATF4, another transcriptional regulator that itself is upregulated during the $\mathrm{UPR}^{\mathrm{mt}}$ (Quiros et al., 2017), and the master regulator PPAR $\gamma$ coactivator $1 \alpha(P G C-1 \alpha)$, which promotes mitochondrial biogenesis by upregulating expression of mitochondrial genes (Fig. 5D). Rotenone treatment yielded increased expression of these master regulators in $4 \mathrm{E}-\mathrm{BP} 1$-overexpressing neurons (Fig. 5D), consistent with the observed expression increases documented for their target genes in $4 \mathrm{E}-\mathrm{BP} 1$-overexpressing neurons (Fig. 5A,C). Immunoblot analysis of HSP60 confirmed a significant increase at the protein level in 4E-BP1-overexpressing neurons compared with control neurons (Fig. 6).

4E-BP1 neuroprotection depends on induction of the UPR ${ }^{\mathrm{mt}}$ To determine whether neuroprotection against rotenone toxicity afforded by $4 \mathrm{E}-\mathrm{BP} 1$ overexpression depends on induction of the $\mathrm{UPR}^{\mathrm{mt}}$, we treated primary cortical neurons from $4 E-B P 1-O E$ transgenic mice and WT littermate controls with rotenone, and performed shRNA knockdown of a transcription factor activator of the $\mathrm{UPR}^{\mathrm{mt}}$, CHOP, or CCAAT/enhancer-binding protein- $\beta$ $(\mathrm{C} / \mathrm{EBP} \beta)$, or heat shock protein $\mathrm{d} 1$ (Hspd1/HSP60), a principal mitochondrial chaperone protein required for an effective $\mathrm{UPR}^{\mathrm{mt}}$, after validating robust knockdown with shRNA-expressing constructs (Fig. 7). Propidium iodide staining revealed that $4 \mathrm{E}-\mathrm{BP} 1$ overexpression rescued toxicity in untreated neurons, in mock-transfected neurons, and in neurons transfected with a scrambled shRNA, compared with WT primary cortical neurons; however, shRNA knockdown of $C H O P, H s p d 1$, or $C / E B P \beta$ prevented neuroprotection in $4 \mathrm{E}-\mathrm{BP} 1$-overexpressing neurons (Fig. $8 A$ ). Evaluation of neurotoxicity by quantification of $\mathrm{LDH}$ release independently corroborated that $4 \mathrm{E}-\mathrm{BP} 1$ overexpression in rotenone-treated neurons only yielded increased neuron survival if expression levels of $C H O P, H s p d 1$, or $C / E B P \beta$ were not reduced by shRNA knockdown (Fig. $8 B$ ). These findings reveal a central role of the $\mathrm{UPR}^{\mathrm{mt}}$ in protecting against rotenone toxicity, and demonstrate that $4 \mathrm{E}-\mathrm{BP} 1$ overexpression relies on $\mathrm{UPR}^{\mathrm{mt}}$ induction for such neuroprotection.

\section{E-BP1 protects neurons against $\alpha$-syn fibril proteotoxicity}

It is well established that $\alpha$-syn ( $\alpha$-syn), a presynaptic protein of uncertain function, plays a central role in the pathogenesis of PD (Polymeropoulos et al., 1997). In the PD brain, the normally soluble $\alpha$-syn protein is converted into insoluble filamentous assemblies, leading to its intraneuronal deposition in Lewy bodies and Lewy neurites, which are histopathological hallmarks of PD and related disorders (Rochet and Lansbury, 2000). Neurotoxicity in PD is closely correlated with the levels of protofibrils of $\alpha$-syn, rather than mature fibrils. These oligomeric forms of $\alpha$-syn may target intracellular organelles and cellular pathways, including mitochondria, the ubiquitin-proteasome system, and the autophagy pathway, leading to neuron dysfunction and cell death. Evidence strongly points to $\alpha$-syn misfolding
A

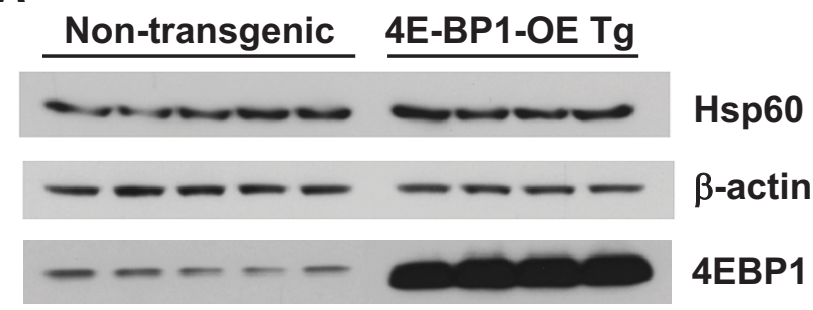

B

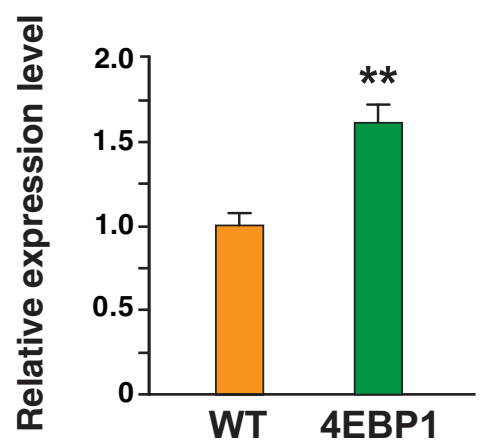

Figure 6. 4E-BP1-overexpressing neurons display increased protein expression of Hsp60. $A$, Immunoblot analysis of DIV14 primary cortical neurons from control and 4E-BP1 transgenic mice. $\beta$-actin served as a loading control, and transgene status was confirmed by immunoblotting for 4E-BP1. B, Densitometry analysis of Hsp60 immunoblotting analysis shown in $\boldsymbol{A}$. ${ }^{* *} p=0.007$ (two-tailed $t$ test; $\mathrm{df}=13 ; \mathrm{EF}=1.9$ ). Error bars indicate SEM.

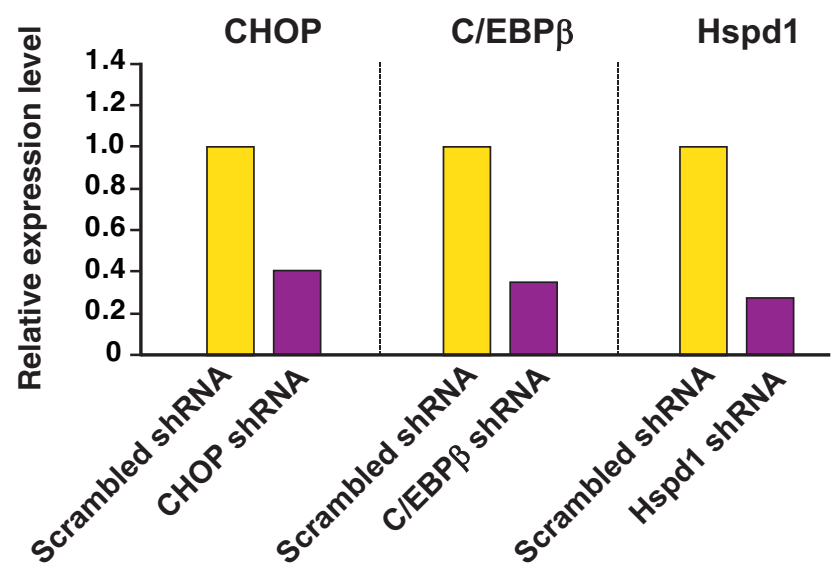

Figure 7. Validation of robust knockdown by lentivirus shRNA constructs. DIV6 primary cortical neurons from control mice were transduced with lentivirus-expressing shRNA, as indicated, for 1 week, after which we isolated RNA and performed qRT-PCR analysis for the gene indicated.

and accumulation in the pathogenesis of PD because of impaired proteostasis and defective mitochondrial quality control (Trojanowski et al., 1998; Singleton et al., 2003; Samii et al., 2004). To model $\alpha$-syn proteotoxicity, a protocol for the production of $\alpha$-syn PFFs has been developed (Volpicelli-Daley et al., 2011), and a method for recapitulating $\alpha$-syn proteotoxicity based on treatment of primary neurons with $\alpha$-syn PFFs has been established (Volpicelli-Daley et al., 2014). To determine whether $4 \mathrm{E}-\mathrm{BP} 1$ overexpression is capable of countering $\alpha$-syn PFF toxicity, we exposed primary hippocampal neurons from $4 E-B P 1-O E$ transgenic mice and WT littermate controls to $\alpha$-syn 
PFFs. Immunostaining for $\alpha$-syn revealed visibly decreased accumulation of $\alpha$-syn inclusions in 4E-BP1-overexpressing neurons (Fig. 9A,B). When we quantified hippocampal neurotoxicity by evaluating nuclear condensation and measuring caspase- 3 activation in individual neurons, we observed markedly reduced toxicity in hippocampal neurons from $4 E-B P 1-O E$ transgenic mice (Fig. 9C,D). Hence, 4E-BP1 overexpression can protect neurons against both $\mathrm{PD}$-relevant chemical toxins and misfolded $\alpha$-syn.

\section{Discussion}

Dietary restriction has been shown to extend lifespan and be neuroprotective in worms, flies, and mice (Mattson, 2005), and numerous studies have linked the beneficial effects of dietary restriction to inhibition of mTOR (Kapahi et al., 2004; Kaeberlein et al., 2005). As previous studies of 4E-BP1 have documented that $4 \mathrm{E}-\mathrm{BP} 1$ is required for lifespan extension on dietary restriction in Drosophila (Zid et al., 2009), and we found that $4 \mathrm{E}-\mathrm{BP} 1$ overexpression can counter metabolic decline and obesity in mice (Tsai et al., 2016), 4E-BP1 activation is likely a major contributor to lifespan extension and antiaging neuroprotection. Consistent with this model, hyperactivation of mTOR has been implicated in the pathogenesis of many neurodegenerative disorders (An et al., 2003; Ravikumar et al., 2004; Zemke et al., 2007; Gkogkas et al., 2013; Santini et al., 2013; Wong, 2013; Pryor et al., 2014; Tang et al., 2015). To determine whether 4E-BP1 can prevent misfolded protein stress and protect against neurodegenerative insults, we derived primary neurons from $4 E-B P 1-O E$ mice. To directly test whether $4 \mathrm{E}-\mathrm{BP} 1$ overexpression can confer neuroprotection against various protein misfolding and neurodegenerative stresses, we compared the health and survival of primary cortical neurons from $4 E-B P 1-O E$ transgenic mice and WT littermate control mice, and documented markedly reduced toxicity in 4E-BP1-overexpressing neurons treated with brefeldin A, rotenone, maneb, or paraquat. While brefeldin A causes accumulation of proteins destined for secretion in the endoplasmic reticulum and thus elicits a general proteostasis stress (Fujiwara et al., 1988), rotenone, maneb, and paraquat promote mitochondrial dysfunction by inhibiting complex I, triggering oxidative stress, and increasing levels of ROS (Drechsel and Patel, 2008), although other effects on mitochondrial quality control have been proposed for these PD-linked toxins (Desplats et al., 2012). Interestingly, 4E-BP1 overexpression also prevented mitochondrial dysfunction that developed in neurons exposed to brefeldin $\mathrm{A}$. These findings indicate that 4E-BP1 overexpression must somehow engage a mitochondrial stress response pathway in neurons to promote mitochondrial function and sustain cellular homeostasis.

To determine the basis for 4E-BP1 activation of a mitochondrial stress response pathway, we evaluated the transcription levels of various mitochondrial metabolic, antioxidant, and chaperone factors in primary neurons overexpressing 4E-BP1, and we observed significant expression increases. In particular, we documented 4E-BP1-dependent upregulation of the expression of genes encoding proteins that comprise the $\mathrm{UPR}^{\mathrm{mt}}$, which was initially described as a mitochondrial-to-nuclear signaling pathway that is activated when misfolded proteins accumulate within mitochondria (Pellegrino et al., 2013). However, beyond this classical model of $U \mathrm{UR}^{\mathrm{mt}}$ activation, further research has demonstrated that the $\mathrm{UPR}^{\mathrm{mt}}$ is activated in response to a diverse array of both mitochondrial and cellular stresses. Indeed, recent studies have shown that activation of the integrated stress response, which turns off global protein translation on regulatory phosphorylation of $\operatorname{eIF} 2 \alpha$, culminates with activation of the UPR ${ }^{\mathrm{mt}}$ (Fiorese et al., 2016; Munch and Harper, 2016; Quiros et al., 2017; Samluk et al., 2019). To test whether 4E-BP1 overexpression, which also reduces global protein synthesis, could be activating the $U P R^{\mathrm{mt}}$, we measured the transcription levels of two master $\mathrm{UPR}^{\mathrm{mt}}$ regulators, CHOP and ATF4, whose transcriptional upregulation has been shown to yield $\mathrm{UPR}^{\mathrm{mt}}$ activation (Zhao et al., 2002; Wang et al., 2018). When we observed significant increases in 
A
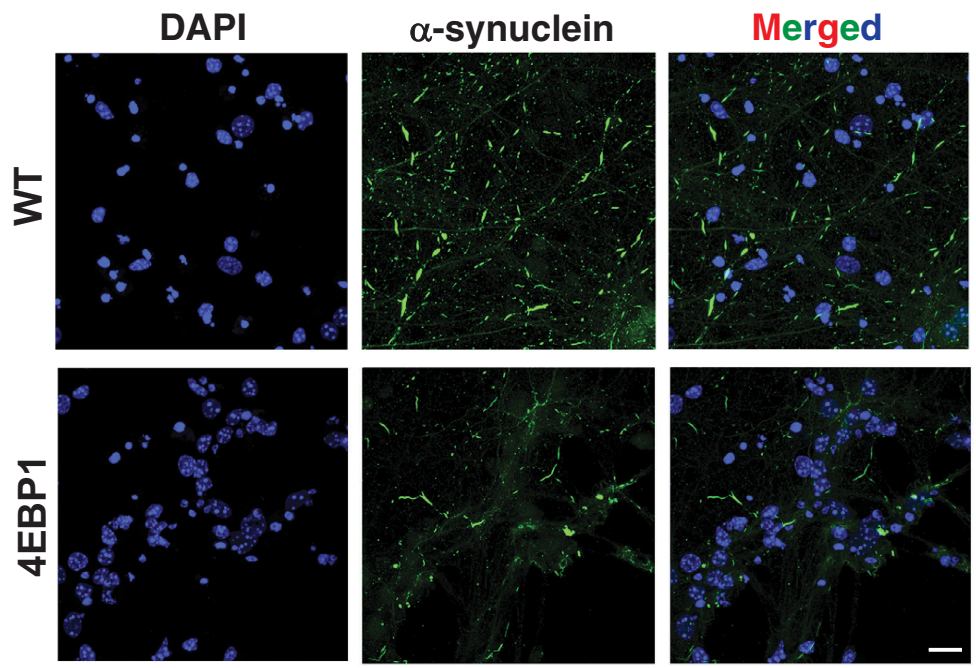

B

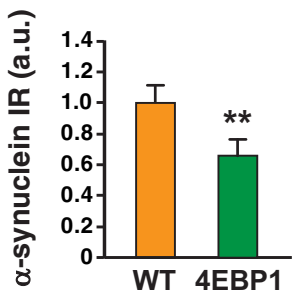

C

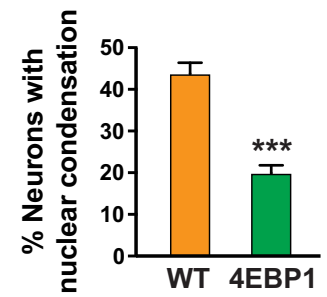

D

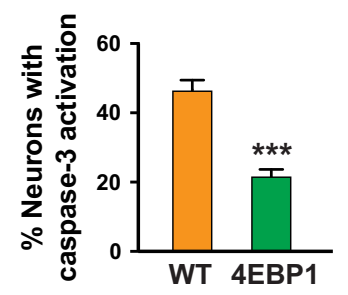

Figure 9. 4E-BP1-overexpressing neurons are protected against $\alpha$-syn PFFs. $\boldsymbol{A}$, DIV10 primary hippocampal neurons from control and 4E-BP1 transgenic mice were treated with $\alpha$-syn PFFs $(100 \mathrm{ng} / \mathrm{ml})$ for 1 week, immunostained with an antibody against phosphorylated $\alpha$-syn, and stained with DAPI. Accumulation of $\alpha$-syn aggregates is visibly reduced in 4E-BP1-overexpressing neurons. Scale bar, $10 \mu \mathrm{m}$. $\boldsymbol{B}$, Densitometry analysis of phospho- $\alpha$-syn immunostaining analysis shown in $\boldsymbol{A}$. $n=5$ biological replicates. ${ }^{* *} p=0.001$ (two-tailed $t$ test; $\mathrm{df}=66$; $\mathrm{EF}=1.0$ ). $C$, DIV10 primary hippocampal neurons from control and 4E-BP1 transgenic mice were treated with $\alpha$-syn PFFs (100 ng/ml) for 1 week and counterstained with DAPI. We then counted the number of neurons showing nuclear condensation. $n=5$ biological replicates; $n \geq 50$ neurons. ${ }^{* * *} p=0.0001$ (two-tailed $t$ test; $d f=66 ; E F=1.9$ ). $D$, DIV10 primary hippocampal neurons from control and 4E-BP1 transgenic mice were treated with $\alpha$-syn PFFs (100 ng/ml) for 1 week, immunostained with an antibody against activated caspase-3, and counterstained with DAPI. We then counted the number of neurons showing activated caspase-3 nuclear staining. $n=5$ biological replicates; $n \geq 50$ neurons. ${ }^{* * *} p=0.0001$ (two-tailed $t$ test; $d f=66$; $E F=1.7$ ). Error bars indicate SEM.

the transcription of $C H O P$ and $A T F 4$ in primary neurons from $4 E-B P 1-O E$ transgenic mice, we repeated our studies of $4 \mathrm{E}-\mathrm{BP} 1$ neuroprotection in combination with shRNA knockdown of CHOP, shRNA knockdown of the CHOP cofactor C/ EBP $\beta$, or shRNA knockdown of HSP60, an essential mitochondrial chaperone for the $\mathrm{UPR}^{\mathrm{mt}}$, and we confirmed that primary neurons overexpressing 4E-BP1 are not rescued from rotenone treatment unless these factors are expressed at normal levels. The mechanism by which $4 \mathrm{E}-\mathrm{BP} 1$ promotes the transactivation of $C H O P$ and ATF4 is yet to be defined, but may involve engagement with the MEK/JNK pathway, as c-Jun phosphorylation can increase CHOP expression (Horibe and Hoogenraad, 2007). Nonetheless, our findings reveal that $4 \mathrm{E}-\mathrm{BP} 1$ is capable of turning on the $\mathrm{UPR}^{\mathrm{mt}}$ in neurons.

A number of studies have found that upregulation of $4 \mathrm{E}$ BP1 could be an effective treatment in models of neurodegenerative diseases, including especially PD. For example, increased dosage of the Drosophila ortholog of mammalian 4E-BP1 strongly suppressed motor phenotypes and dopaminergic neuron degeneration in Drosophila Parkin and PINK1 loss-of-function models of PD (Tain et al., 2009). Furthermore, 4E-BP1 has been shown to be a substrate of LRRK2 (Imai et al., 2008), mutations of which account for the most common genetic form of familial PD. As mutant G2019S LRRK2, the most common PD-causing allele in the human population, results in increased phosphorylation of 4E-BP1 (Imai et al., 2008), reduced 4E-BP1 function may contribute to $\mathrm{PD}$ pathogenesis. To further examine the connection between 4E-BP1 function and PD, we exposed primary neurons to three different PD-linked toxins (rotenone, maneb, or paraquat), and we documented significant neuroprotection in neurons from 4E-BP1-OE transgenic mice. We also tested whether 4E-BP1 could prevent $\alpha$-syn neurotoxicity by treating $4 \mathrm{E}-\mathrm{BP} 1$-overexpressing primary hippocampal neurons with $\alpha$-syn PFFs, and we observed marked reductions in $\alpha$-syn aggregation and neurotoxicity, thus validating that $4 \mathrm{E}-\mathrm{BP} 1$ is also a powerful suppressor of the central player in the PD pathogenic cascade. While previous studies have attributed 4E-BP1 neuroprotection to reduced protein synthesis, we have now extended the understanding of $4 \mathrm{E}-\mathrm{BP} 1$ neuroprotection by discovering that $4 \mathrm{E}$ $\mathrm{BP} 1$ activation induces the $\mathrm{UPR}^{\mathrm{mt}}$ in neurons. This finding underscores the broad neurotherapeutic potential for $4 \mathrm{E}-\mathrm{BP} 1$ activation, as activation of the $\mathrm{UPR}^{\mathrm{mt}}$ can potently reduce Alzheimer's disease-associated amyloid- $\beta$ proteotoxicity (Sorrentino et al., 2017). Although much effort has been focused on developing compounds to inhibit mTORC1, as mTORC1 inhibition can activate autophagy and derepress $4 \mathrm{E}$ $\mathrm{BP} 1$, this therapeutic strategy has been complicated by concern over off-target effects of broad mTOR inhibition and by unease regarding the potential deleterious effects of inducing autophagy when the autophagy pathway is impaired and autophagic flux is blocked in neurodegeneration because of misfolded protein stress in diseased neurons. For these reasons, increasing the expression of $4 \mathrm{E}-\mathrm{BP} 1$ or enhancing $4 \mathrm{E}$ BP1 activation by maintaining abundant levels of dephosphorylated $4 \mathrm{E}-\mathrm{BP} 1$ may represent an appealing therapeutic opportunity for treating a variety of neurodegenerative diseases, including especially PD.

\section{References}

An WL, Cowburn RF, Li L, Braak H, Alafuzoff I, Iqbal K, Iqbal IG, Winblad B, Pei JJ (2003) Up-regulation of phosphorylated/activated p70 S6 kinase and its relationship to neurofibrillary pathology in Alzheimer's disease. Am J Pathol 163:591-607.

Betarbet R, Sherer TB, MacKenzie G, Garcia-Osuna M, Panov AV, Greenamyre JT (2000) Chronic systemic pesticide exposure reproduces features of Parkinson's disease. Nat Neurosci 3:1301-1306. 
Dawson TM, Dawson VL (2003) Molecular pathways of neurodegeneration in Parkinson's disease. Science 302:819-822.

Desplats P, Patel P, Kosberg K, Mante M, Patrick C, Rockenstein E, Fujita M, Hashimoto M, Masliah E (2012) Combined exposure to Maneb and Paraquat alters transcriptional regulation of neurogenesis-related genes in mice models of Parkinson's disease. Mol Neurodegener 7:49.

Drechsel DA, Patel M (2008) Role of reactive oxygen species in the neurotoxicity of environmental agents implicated in Parkinson's disease. Free Radic Biol Med 44:1873-1886.

Dubinsky AN, Dastidar SG, Hsu CL, Zahra R, Djakovic SN, Duarte S, Esau CC, Spencer B, Ashe TD, Fischer KM, MacKenna DA, Sopher BL, Masliah E, Gaasterland T, Chau BN, Pereira de Almeida L, Morrison BE, La Spada AR (2014) Let-7 coordinately suppresses components of the amino acid sensing pathway to repress mTORC1 and induce autophagy. Cell Metab 20:626-638.

Fiorese CJ, Schulz AM, Lin YF, Rosin N, Pellegrino MW, Haynes CM (2016) The transcription factor ATF5 mediates a mammalian mitochondrial UPR. Curr Biol 26:2037-2043.

Fujiwara T, Oda K, Yokota S, Takatsuki A, Ikehara Y (1988) Brefeldin A causes disassembly of the Golgi complex and accumulation of secretory proteins in the endoplasmic reticulum. J Biol Chem 263:1854518552.

Gkogkas CG, Khoutorsky A, Ran I, Rampakakis E, Nevarko T, Weatherill DB, Vasuta C, Yee S, Truitt M, Dallaire P, Major F, Lasko P, Ruggero D, Nader K, Lacaille JC, Sonenberg N (2013) Autism-related deficits via dysregulated eIF4E-dependent translational control. Nature 493:371-377.

Hara T, Nakamura K, Matsui M, Yamamoto A, Nakahara Y, SuzukiMigishima R, Yokoyama M, Mishima K, Saito I, Okano H, Mizushima N (2006) Suppression of basal autophagy in neural cells causes neurodegenerative disease in mice. Nature 441:885-889.

Horibe T, Hoogenraad NJ (2007) The CHOP gene contains an element for the positive regulation of the mitochondrial unfolded protein response. PLoS One 2:e835.

Imai Y, Gehrke S, Wang HQ, Takahashi R, Hasegawa K, Oota E, Lu B (2008) Phosphorylation of 4E-BP by LRRK2 affects the maintenance of dopaminergic neurons in Drosophila. EMBO J 27:2432-2443.

Jovaisaite V, Mouchiroud L, Auwerx J (2014) The mitochondrial unfolded protein response, a conserved stress response pathway with implications in health and disease. J Exp Biol 217:137-143.

Kaeberlein M, Powers RW 3rd, Steffen KK, Westman EA, Hu D, Dang N, Kerr EO, Kirkland KT, Fields S, Kennedy BK (2005) Regulation of yeast replicative life span by TOR and Sch9 in response to nutrients. Science 310:1193-1196.

Kapahi P, Zid BM, Harper T, Koslover D, Sapin V, Benzer S (2004) Regulation of lifespan in Drosophila by modulation of genes in the TOR signaling pathway. Curr Biol 14:885-890.

King MA, Hands S, Hafiz F, Mizushima N, Tolkovsky AM, Wyttenbach A (2008) Rapamycin inhibits polyglutamine aggregation independently of autophagy by reducing protein synthesis. Mol Pharmacol 73:10521063.

Komatsu M, Waguri S, Chiba T, Murata S, Iwata J, Tanida I, Ueno T, Koike M, Uchiyama Y, Kominami E, Tanaka K (2006) Loss of autophagy in the central nervous system causes neurodegeneration in mice. Nature 441:880-884.

Labbadia J, Morimoto RI (2015) The biology of proteostasis in aging and disease. Annu Rev Biochem 84:435-464.

Lipton JO, Sahin M (2014) The neurology of mTOR. Neuron 84:275-291.

Luk KC, Kehm VM, Zhang B, O’Brien P, Trojanowski JQ, Lee VM (2012) Intracerebral inoculation of pathological alpha-synuclein initiates a rapidly progressive neurodegenerative alpha-synucleinopathy in mice. J Exp Med 209:975-986.

Luk KC, Song C, O’Brien P, Stieber A, Branch JR, Brunden KR, Trojanowski JQ, Lee VM (2009) Exogenous alpha-synuclein fibrils seed the formation of Lewy body-like intracellular inclusions in cultured cells. Proc Natl Acad Sci USA 106:20051-20056.

Maiese K, Chong ZZ, Shang YC, Wang S (2013) mTOR: on target for novel therapeutic strategies in the nervous system. Trends Mol Med 19:51-60.

Mattson MP (2005) Energy intake, meal frequency, and health: a neurobiological perspective. Annu Rev Nutr 25:237-260.
Munch C, Harper JW (2016) Mitochondrial unfolded protein response controls matrix pre-RNA processing and translation. Nature 534:710713.

Nargund AM, Pellegrino MW, Fiorese CJ, Baker BM, Haynes CM (2012) Mitochondrial import efficiency of ATFS-1 regulates mitochondrial UPR activation. Science 337:587-590.

Pace MC, Xu G, Fromholt S, Howard J, Crosby K, Giasson BI, Lewis J, Borchelt DR (2018) Changes in proteome solubility indicate widespread proteostatic disruption in mouse models of neurodegenerative disease. Acta Neuropathol 136:919-938.

Pellegrino MW, Nargund AM, Haynes CM (2013) Signaling the mitochondrial unfolded protein response. Biochim Biophys Acta 1833: $410-416$.

Polymeropoulos MH, Lavedan C, Leroy E, Ide SE, Dehejia A, Dutra A, Pike B, Root H, Rubenstein J, Boyer R, Stenroos ES, Chandrasekharappa S, Athanassiadou A, Papapetropoulos T, Johnson WG, Lazzarini AM, Duvoisin RC, Di Iorio G, Golbe LI, Nussbaum RL (1997) Mutation in the alpha-synuclein gene identified in families with Parkinson's disease. Science 276:2045-2047.

Pryor WM, Biagioli M, Shahani N, Swarnkar S, Huang WC, Page DT, MacDonald ME, Subramaniam S (2014) Huntingtin promotes mTORC1 signaling in the pathogenesis of Huntington's disease. Sci Signal 7:ra103.

Quiros PM, Prado MA, Zamboni N, D'Amico D, Williams RW, Finley D, Gygi SP, Auwerx J (2017) Multi-omics analysis identifies ATF4 as a key regulator of the mitochondrial stress response in mammals. J Cell Biol 216:2027-2045

Ravikumar B, Vacher C, Berger Z, Davies JE, Luo S, Oroz LG, Scaravilli F, Easton DF, Duden R, O'Kane CJ, Rubinsztein DC (2004) Inhibition of mTOR induces autophagy and reduces toxicity of polyglutamine expansions in fly and mouse models of Huntington disease. Nat Genet 36:585595.

Rochet JC, Lansbury PT Jr (2000) Amyloid fibrillogenesis: themes and variations. Curr Opin Struct Biol 10:60-68.

Roede JR, Jones DP (2014) Thiol-reactivity of the fungicide maneb. Redox Biol 2:651-655

Samii A, Nutt JG, Ransom BR (2004) Parkinson's disease. Lancet 363:17831793.

Samluk L, Urbanska M, Kisielewska K, Mohanraj K, Kim MJ, Machnicka K, Liszewska E, Jaworski J, Chacinska A (2019) Cytosolic translational responses differ under conditions of severe short-term and long-term mitochondrial stress. Mol Biol Cell 30:1864-1877.

Santini E, Huynh TN, MacAskill AF, Carter AG, Pierre P, Ruggero D, Kaphzan H, Klann E (2013) Exaggerated translation causes synaptic and behavioural aberrations associated with autism. Nature 493:411415.

Schmidt EK, Clavarino G, Ceppi M, Pierre P (2009) SUnSET, a nonradioactive method to monitor protein synthesis. Nat Methods 6:275-277.

Sherer TB, Kim JH, Betarbet R, Greenamyre JT (2003) Subcutaneous rotenone exposure causes highly selective dopaminergic degeneration and alpha-synuclein aggregation. Exp Neurol 179:9-16.

Singleton AB, Farrer M, Johnson J, Singleton A, Hague S, Kachergus J, Hulihan M, Peuralinna T, Dutra A, Nussbaum R, Lincoln S, Crawley A, Hanson M, Maraganore D, Adler C, Cookson MR, Muenter M, Baptista M, Miller D, Blancato J, et al. (2003) alpha-Synuclein locus triplication causes Parkinson's disease. Science 302:841.

Sorrentino V, Romani M, Mouchiroud L, Beck JS, Zhang H, D'Amico D, Moullan N, Potenza F, Schmid AW, Rietsch S, Counts SE, Auwerx J (2017) Enhancing mitochondrial proteostasis reduces amyloid-beta proteotoxicity. Nature 552:187-193.

Tain LS, Mortiboys H, Tao RN, Ziviani E, Bandmann O, Whitworth AJ (2009) Rapamycin activation of 4E-BP prevents parkinsonian dopaminergic neuron loss. Nat Neurosci 12:1129-1135.

Tang Z, Ioja E, Bereczki E, Hultenby K, Li C, Guan Z, Winblad B, Pei JJ (2015) mTor mediates tau localization and secretion: implication for Alzheimer's disease. Biochim Biophys Acta 1853:1646-1657.

Taylor JP, Hardy J, Fischbeck KH (2002) Toxic proteins in neurodegenerative disease. Science 296:1991-1995.

Trojanowski JQ, Goedert M, Iwatsubo T, Lee VM (1998) Fatal attractions: abnormal protein aggregation and neuron death in Parkinson's disease and Lewy body dementia. Cell Death Differ 5:832-837. 
Tsai S, Sitzmann JM, Dastidar SG, Rodriguez AA, Vu SL, McDonald CE, Academia EC, O'Leary MN, Ashe TD, La Spada AR, Kennedy BK (2015) Muscle-specific 4E-BP1 signaling activation improves metabolic parameters during aging and obesity. J Clin Invest 125:2952-2964.

Tsai SY, Rodriguez AA, Dastidar SG, Del Greco E, Carr KL, Sitzmann JM, Academia EC, Viray CM, Martinez LL, Kaplowitz BS, Ashe TD, La Spada AR, Kennedy BK (2016) Increased 4E-BP1 expression protects against diet-induced obesity and insulin resistance in male mice. Cell Rep 16:1903-1914

Volpicelli-Daley LA, Luk KC, Patel TP, Tanik SA, Riddle DM, Stieber A, Meaney DF, Trojanowski JQ, Lee VM (2011) Exogenous alpha-synuclein fibrils induce Lewy body pathology leading to synaptic dysfunction and neuron death. Neuron 72:57-71.

Volpicelli-Daley LA, Luk KC, Lee VM (2014) Addition of exogenous alphasynuclein preformed fibrils to primary neuronal cultures to seed recruitment of endogenous alpha-synuclein to Lewy body and Lewy neurite-like aggregates. Nat Protoc 9:2135-2146.

Wang S, Gao K, Liu Y (2018) UPR(mt) coordinates immunity to maintain mitochondrial homeostasis and animal fitness. Mitochondrion 41:9-13.

Wong M (2013) Mammalian target of rapamycin (mTOR) pathways in neurological diseases. Biomed J 36:40-50.

Zemke D, Azhar S, Majid A (2007) The mTOR pathway as a potential target for the development of therapies against neurological disease. Drug News Perspect 20:495-499.

Zhao Q, Wang J, Levichkin IV, Stasinopoulos S, Ryan MT, Hoogenraad NJ (2002) A mitochondrial specific stress response in mammalian cells. EMBO J 21:4411-4419.

Zid BM, Rogers AN, Katewa SD, Vargas MA, Kolipinski MC, Lu TA, Benzer S, Kapahi P (2009) 4E-BP extends lifespan upon dietary restriction by enhancing mitochondrial activity in Drosophila. Cell 139:149-160. 